\title{
Audiobooks and Print Narrative: Similarities in Text Experience
}

\section{Introduction}

Although audiobooks appeared shortly after Edison's invention of the cylinder phonograph, recordings of long-form narrative did not become properly widespread until the recent introduction of high-capacity, and highly portable, digital audio players (Rubery 2011b). It is therefore natural that audiobooks are debated as if they were an innovation of today. A continuation of sorts of the once prevalent communal reading aloud, the audiobook has been praised for offering a number of aesthetic benefits over silent reading. Through the presence of an actual human voice, every single word can seem affectively charged. Through prosody and voice modulation, interpretive paths are offered to the listener that might not have opened up otherwise. Through multiple recordings of single texts by different performers, the protean nature of narrative reception becomes clearer than ever (for a multi-author volume taking up these benefits in case studies of specific audiobooks, see Rubery 2011a). While the general sense of novelty has given rise to new forms of education activism, ${ }^{1}$ systematic scholarship on the contemporary audiobook experience remains sparse (for a notable exception, see Wittkower 2011). As usual when a new technology takes over culture narrowly defined, audiobooks also have their adversaries (e.g., Birkerts 1994). Obviously, some aspects of text experience go missing when a narrative is converted from print to sound. Pioneering research (Mangen 2014) is now being produced investigating analogous losses in the transition from print to digital reading. The worry seems warranted with regard to both new media. But audiobooks, unlike e-books, have not been seriously suggested to eventually replace print, or silent reading, across the board. A discussion of the innumerable differences between audiobooks and print, albeit valuable, is therefore not as pressing as it is in the case of e-reading. The present chapter aims to tackle a more modest task: Instead of pointing at more or less apparent differences, I will focus on a limited number of underexplored yet crucial similarities.

1 The LibriVox project, for instance, is an on-line collection containing thousands of free audiobooks recorded by volunteers worldwide. Many of these audiobooks belong to the expository genre, including classical works of philosophy (see Hancher 2011). 
The focus on similarities rather than differences is motivated by the current state of the audiobook debate. Comparisons between audiobook listening and print reading often boil down to the fact that audiobook listening, in contrast to reading, is not self-paced, and that this imposes limitations on the recipient's continuous in-depth reflection (Birkerts 1994; Toolan 2008). As a result, audiobook listening is considered a shallow alternative to reading. Indeed, should the listener continuously muse over deeper meanings or intricate details in the text, she would soon lose track of the narrative. Seen as a disadvantage, this inability to systematically reflect on the text can be critical. On the other hand, audiobooks redirect our theoretical attention to features of the narrative experience that cater to its other functions. Rather than stimulating systematic reflection, these features serve purely hedonistic purposes such as daydreaming or, more generally, aesthetic pleasure across sensory modalities. Although they may be more dominant in audiobooks than in print reading, I will argue that they are essentially inherent to narrative text reception and shared across the two media. The massive remediation (see also Bolter and Grusin 2000) from print to audio only makes their inherence in reading more conspicuous now than before. I will further argue that these features are to some degree properly functional, i.e., beneficial to the recipient.

Throughout the chapter, the following similarities between audiobook listening and print reading will be explored:

1st similarity: The enactive nature of the recipient's mental imagery;

2nd similarity: The relative poverty of the recipient's attention;

3rd similarity: The occasional richness of the recipient's phenomenal consciousness.

These features of reading seem to have been largely overlooked, or even expressly contradicted, in much of narrative scholarship. This may be partly due to the assumption, traditionally prevailing in the literary academia, that reading is meant to primarily serve systematic, analytical, distanced reflection (see, e.g., Fialho, Zyngier, and Miall 2011).

My argument concerning the three similarities will have a three-step structure. For each similarity, I will begin by isolating an intuition from the audiobook literature concerning an alleged difference between the two media. Then I will question this intuition by pointing at an underlying misconception about print reading, a misconception common among narrative and literary scholars at large. For every intuition, there will be one misconception to be refuted. In refuting it, I will refer to empirical findings from various research disciplines (e.g., cognitive psychology, neuroscience, empirical studies of literature and media), but I will also quote a concrete example of literary narrative for a more 
hands-on illustration. Finally, I will explain the possible consequences and functions of the similarity in question as illustrated by the previous steps.

\section{Defining Reading and Listening}

Before proceeding to the main argument, a closer definition of the two practices in question - i.e., print reading and audiobook listening - is needed. There are diverse ways of reading a printed narrative and diverse ways of listening to an audiobook. For the purposes of the present chapter, this variation will be delimited by a primary focus on the adult population with developed reading skills and relatively solid reading habits. By print reading (or simply reading), I will thus refer to such reading of printed fictional narrative that is silent, solitary, voluntary, more or less continuous, and done for leisure. Our exemplary reading situation can take place in a single environment or across several different environments, even within a short span of time, e.g., during the daily commute.

A printed book is portable, but the audiobook is essentially defined by its portability. In the target population, audiobooks are largely played during routine tasks (Rubery 2011b) such as travel or physical exercise. By audiobook listening (or simply listening), I will thus refer to such listening to a digital recording of a fictional narrative wherein the listener uses a portable device with a headset. This enables her not only to navigate across environments, but also to experience the narrative in a way most akin to solitary reading. ${ }^{2}$ Our exemplary listening situation is likewise voluntary, more or less continuous, and done for leisure. For even closer adherence to the exemplary reading scenario, the audiobook in question consists preferably of a narrative originally written to be silently read, i.e., a novel or short story that has been remediated into an audiobook with a single voice performer. In the contemporary media ecology, this appears to be a major usage.

The two exemplary situations should be understood as prototypes allowing some degree of variation. What I will say about the possible workings of mental imagery, attention, and phenomenal consciousness in these exemplary situations may likewise be true for scenarios diverging on one or several of the above characteristics. At the same time, numerous variables will need to remain wholly unaccounted for, especially those concerning differences between indi-

2 In this respect, similar types of narrative experience may be found in audio guides or experimental performance art such as the mobile phone theatre (see also contributions by Mildorf and Festjens, this volume). 
vidual readers' personality traits and instantaneous dispositions. What is certain is that the near-multitasking inherent in the exemplary listening situation enables, by definition, little systematic reflection of the kind typically expected by literary scholars. ${ }^{3}$

Moreover, unlike pupils cheating on reading assignments, adults with developed reading skills and relatively solid reading habits rarely ask themselves whether they want to read a narrative or listen to one instead. Rather, they choose between the two media based on their instantaneous situation and the type of reception it affords. For instance, as long as they need to walk, print is out of the question. Some frequent scenarios, such as passive transportation, partly overlap in their affordances for both media. Highly distractive transportation environments, however, may foreclose deeper reflection in the case of print reading as well, yet another reason to look for alternative common denominators.

Finally, no inquiry into the experiences of a group as large and diverse as the adult population with developed reading skills and relatively solid reading habits can ever be considered comprehensive. There is no way to account for the virtually endless differences across individuals and individual scenarios within the scope of a single essay. Whenever possible, I will therefore model a hypothetical recipient along the statistical constructs put forward by empirical scholarship, but it would be naïve to suppose that I am fully unaffected by my own introspections, as reader and listener, in doing so. For the sake of simplicity, a distinction will likewise be maintained throughout the chapter between academic (i.e., distanced, analytical) and non-academic (i.e., hedonistic) reception practices. It should be noted, however, that this distinction is ultimately an artificial one, and that insofar as literary scholars are human beings, their ways of reading and listening will always bear traces of the non-academic kind of practice. Vice versa, many leisure readers may sometimes spontaneously employ reading strategies resembling those of literary scholars.

3 Research on multitasking (Schumacher et al. 2001; Murphy Paul 2013) indicates that highly complex cognitive operations require undivided attention and are thus exempt from multitasking proper, which can at best comprise two very undemanding activities, e.g., listening to the weather report while folding laundry. 


\section{First Similarity: The Enactive Nature of the Recipient's Mental Imagery}

\subsection{First Intuition}

Mental imagery amounts to a person's subjective sense of perceiving an overtly absent physical reality. Across research disciplines, mental imagery is often dealt with reductively, on one or more levels:

Firstly, readers' mental imagery is typically understood to encompass vicarious perceptions relating only to the referents mentioned or implied in a text (referential imagery). Meanwhile, vicarious perceptions of the words of the text as if pronounced out loud (verbal imagery) are given little or no attention (see also Kuzmičová 2014). The latter, verbal type of mental imagery is ubiquitous in silent reading and obviously relevant to print-to-audio remediation. In fact, the listener's inability to freely imagine the voices of characters and narrators has been highlighted by some critics as a key argument against the audiobook medium (Rubery 2011b). However, as the present chapter focuses on the similarities rather than differences between audiobook and print, I accept this first level of reduction, constraining the recipient's mental imagery to the referential domain.

Secondly, mental imagery at large, including mental imagery in reading, is frequently reduced to visual imagery alone (Connell and Lynott 2012). Mental imagery in other sensory modalities - whether exteroceptive (e.g., touch, hearing, smell, taste), interoceptive (e.g., pain), proprioceptive (e.g., balance), or kinesthetic (e.g., acceleration) - is rarely studied systematically or even acknowledged, especially in fields like narrative theory (see also Kuzmičová 2014). It is this second level of reduction that needs to be refuted if we are to gain a better understanding of narrative text experience across the two media in question. But let us follow the three-step structure announced above, beginning with a recurrent intuition concerning audiobook listening.

The intuition goes: Compared to print, audiobooks are better suited for eliciting mental imagery. The intuition has appeared in theoretical (Wittkower 2011) and empirical-theoretical (Toolan 2008) literature as well as in popular writing (Laidman 2012). The reasoning behind it is loosely grounded in a notion of within-modality interference. Within-modality interference, a phenomenon explored in the experimental cognitive sciences (De Beni and Moè 2003), entails that mental imaging in a given sensory modality becomes more difficult if a physical stimulus is simultaneously present in the same modality. By this token, it should be comparably difficult to visualize the contents of a narrative while having to decode words on a page, a task that is highly visually taxing. Audiobooks, engag- 
ing the auditory modality instead, should alleviate the difficulty. The intuition has obvious appeal. Yet if we consider our exemplary listening situation, which usually involves some degree of visual environment perception, its appeal becomes less obvious. One's eyes may be somewhat less busy during a walk with a headset on as compared to during reading, but they are busy nevertheless. I will return to within-modality interference as applied to the exemplary situations soon, after raising a more fundamental point of criticism.

\subsection{First Misconception}

My criticism is that the intuition is based on a misconception concerning mental imagery, a misconception that can be expressed as follows: The recipient's mental imagery consists in visual pictures before the mind's eye. Vision is the dominant sense in humans, and mental images are often experienced to have a visual component (see also Spence and Deroy 2013). But static visual pictures or even filmic snippets in the head are inaccurate as a general metaphor for mental imagery elicited by narrative, even though they are by far the most widespread in narrative and literary scholarship (Jajdelska et al. 2010; Troscianko 2013). The metaphor presupposes that the imager's embodied stance vis-à-vis the imaged contents is one of a detached spectator, with little or no vicarious involvement in the contents themselves. While readers' mental images, especially those prompted by elaborate static descriptions, may occasionally be experienced as resembling detached pictures in the head, there is substantial evidence that mental imagery is not picturesque but largely enactive instead (Kuzmičová 2012). ${ }^{4}$ Enactive mental images cast us in three-dimensional situations rather than consisting of two-dimensional visual projections. The imager's stance is one of a physically involved experiencer rather than a detached spectator. Consider, for instance, the following passage from Ernest Hemingway's novel The Garden of Eden:

[David and Catherine] were always hungry but they ate well. They were hungry for breakfast which they ate at the cafe, ordering brioche and café au lait and eggs, and the type of preserve they chose and the manner in which the eggs were to be cooked was an excitement. [...] On this morning there was brioche and red raspberry preserve and the eggs were boiled and there was a pat of butter that melted as they stirred them and salted them lightly and ground pepper over them in the cups. (Hemingway 1995 [1986], 4)

4 Some critics of the picture metaphor (Thompson 2007; Troscianko 2013) even suggest that non-enactive, picturesque mental imagery is outright impossible. 
A visual picture before the mind's eye, static or moving, of the above contents may present the imager with the sight of two human figures seated at a café table, eating breakfast. An enactive mental image of the same contents, on the other hand, makes the imager partly adopt the embodied stance of the two adventurous eaters. Compared to mere visual pictures, such enactive imagery has an ampler sensory range. An enactive image of David and Catherine enjoying their breakfast, for instance, would likely enlist the modalities of taste and smell (in relation to the food), touch and movement (in relation to the manual handling of the food), or at least a subset of these. Evidence from neuroimaging, behavioural, and self-report experiments, suggests that mental imagery is grounded in actual sensory and motor physiological processes. Verbally induced flavour images, comprising taste and smell (Eardley and Pring 2011), as well as verbally induced motor representations, comprising touch and movement (Fischer and Zwaan 2008), have been found to activate corresponding areas of the brain and to interfere with overt activity in respective modalities (e.g., sucking candy, rotating a knob). Even if the visual component of the reader's image were not overridden by these other modalities, it would certainly not amount to a finite picture or movie snippet. It would rather resemble the fragmentary sight of a three-dimensional set of objects inviting bodily interaction.

\subsection{First Set of Consequences for Text Experience}

Now that the recipient's mental imagery has been redefined in terms of enactment, what does the redefinition mean for the intuition that audiobooks prompt more mental imagery than print? Firstly, the visual stimuli in print decoding consist invariably in flat monochrome signs on a page, having little in common with the multimodal sensations (Spence and Deroy 2013) experienced in enactive imagery. Thus the sheer activity of reading does not necessarily have to interfere, or not too strongly, with mental imagery as redefined above. After all, generations of print readers have acknowledged experiencing mental images, even very vivid ones. Secondly, our exemplary listening situation clearly entails more bodily activity, and with it more potential physical stimulation in the different sensory modalities, than any conceivable reading situation. Based on this latter observation alone, one could easily draw the conclusion that due to within-modality interference, listening should afford less mental imagery overall than reading - not more. A reader's body is static, so there should be a lesser risk of enactive imagery becoming suppressed by real action and perception (see, e.g., Chapelle Wojciehowski and Gallese 2011 for this line of reasoning). 
At a closer look, things are not as straightforward. Imagine listening to the above narrative passage during a walk with a headset on. Although any environment is potentially stimulating in any sensory modality, one's conscious experience rarely encompasses the entire sensory array. It is true that if you happen to be physically tired, your motor experience can become rather salient as you begin to focus on your aching muscles. Walking may then indeed prevent you from conjuring mental images corresponding to motor tasks, e.g., those of stirring, salting, or peppering a boiled egg. Other sensory features of your activity may be far less conspicuous, though. For instance, smells may occur in the environment (exhaust fumes, trees in bloom), but you may not notice them when it is time to conjure an olfactory mental image of freshly brewed coffee. If you do happen to notice these smells and are thus prevented from imaging fictional ones, there is still plenty left for you to image in the gustatory modality. And unless you are navigating a largely unfamiliar terrain that forces you to stay visually focused, visual input does not entirely prevent you from catching a glimpse of David and Catherine's enticing breakfast table.

Moreover, it should be noted that print reading is never spared from environmental sensory stimulation either, even if reading environments may not change as dynamically as listening environments in the course of a single session. Between listening and reading, it is thus impossible to determine that one activity invites more mental imagery than the other. Rather, imagery affordances always result from the instantaneous configuration of sensory features in the environment, the recipient's readiness to perceive these features, and the specific subset of sensory modalities potentially addressed by the narrative. ${ }^{5}$

Finally, what does the redefined notion of mental imagery add to our understanding of the functions of narrative across the two media? One's psychological set is different in conjuring enactive mental imagery as compared to mentally inspecting a detached visual picture. An enactive image has more of a holistic potential, tapping more deeply into the affective charges of the narrative in question (Jajdelska et al. 2010). In a fraction of a second, it makes the imager experience rather than contemplate the situation rendered in the narrative. Inspecting an image or contemplating a situation would entail some degree of the intellectual distance commended by literary scholarship. Meanwhile, enacting the life of a narrative character, perhaps including some of the corresponding emotions, suggests other receptive functions than systematic reflection.

5 Close sensory overlaps between narrative and environment can, in some cases, result in an enhancement of mental imagery rather than its suppression, see Section 5.2 below. 
Let us once again consider the typical scenario in which an adult person with developed reading skills resorts to playing an audiobook on a portable device. Often her alternative option is to walk, exercise, or travel without any narrative input at all (Laidman 2012). What would this alternative option offer her in terms of mental activity? Her mind would most likely be allowed to wander freely in the default mode (see, e.g., Smallwood et al. 2013), engaging in the sort of self-centred daydreaming distinctive for idle minutes on public transit or physically demanding minutes of a jogging session. An important aspect of such daydreaming, then, is the compulsive mental re-enactment of previously experienced life situations or fantasizing about future ones, with more or less mental imagery involved. What audiobooks - similarly to print - do is they bring into these daydreaming scenarios a unique shift in perspective. The life daydreamt about is not the recipient's own but somebody else's. The daily dose of daydreaming partly changes character to non-self-centred daydreaming.

The narrative quoted earlier in this section invites the recipient to mentally enact more than just opulent continental meals. In fact, the joyous material life of the protagonists eventually comes into stark contrast with the intricacies of a deteriorating relationship. Mental images of idyllic honeymoon settings can then be experienced in unusual concert with utterly ambiguous, distressful emotions. The power of such highly complex daydreams to impact the recipient's personality (Oatley 2011) and mental wellbeing (Dowrick et al. 2012) has been empirically proven. Non-self-centred daydreaming, afforded by audiobooks and print alike, may thus be considered no less beneficial to mental life than the systematic reflection supposedly impeded by the audiobook.

\section{Second Similarity: The Relative Poverty of the Recipient's Attention}

\subsection{Second Intuition}

The second intuition that needs to be put into perspective may be expressed as follows: Compared to print, audiobooks invite more inattentive processing. Or perhaps even more strongly: Unlike print, audiobooks invite inattentive processing. The intuition has appeared in theoretical writing (Wittkower 2011; more strongly in Birkerts 1994) as well as in popular scientific writing (Jaffe 2014). To some degree, it (or at least its weaker version) is certainly true. As already mentioned, the exemplary listening situation involves more potential stimuli from the continuously visible and changing environment, and with them more possible distrac- 
tion. The degree to which the intuition can be further embraced or questioned depends on what is meant by inattentive processing.

From the viewpoint of text experience, at least two different notions of inattention can be distinguished: firstly, there are instances of the recipient becoming more or less distinctly aware of paying attention to other matters than the narrative being read or listened to. This phenomenon is widely known as mind wandering. Although recent empirical studies have shown that listening to a (popular scientific) text elicits slightly more mind wandering than the (digital) silent reading of the same text (Varao Sousa, Carriere and Smilek 2013), it would be misguided to believe that mind wandering is absent or uncommon in reading (Dixon and Bortolussi 2013). Mind wandering occurs in expert readers and novices alike. Moreover, the recipient's mind does not always wander off to matters entirely unrelated to the narrative. Convergent evidence suggests that elaborate mental digressions to personal life experiences directly cued by a (print) narrative can yield strong aesthetic effects (Miall 2006).

The main focus of the present section, however, is a second, broader notion of inattention. On this notion, inattention is simply the inverse of a recipient's real-time awareness of the specific wording of a stretch of text and/or its possible meaning, also in relation to previous stretches of the same text. In this sense, an instance of inattention can, but does not have to, coincide with or be immediately preceded by mind wandering. To the recipient, inattention in this sense can only become truly manifest when a narrative passage suddenly stops making sense. To a third-person observer, it can become manifest in the recipient's failing of a memory or comprehension check. In most cases, it does not become manifest at all.

\subsection{Second Misconception}

In terms of inattention so defined, the focal intuition of the present section relies on the following misconception: Readers of print narrative commonly attend to textual detail. This view of reading seems to underpin much of advanced literary education as well as literary scholarship. Educators often express their surprise at students failing to report and analyse their assigned reading materials in terms of various subtle connections and verbal nuances. In the words of Louise M. Rosenblatt, a pioneer of modern literary education: "The reader must pay attention to all that these words, and no others, these words, moreover, in a particular sequence, summon up. [...] What is lived through is felt constantly to be linked with the words” (Rosenblatt 1994 [1978], 29). Rosenblatt speaks of poetry 
reading primarily, but the concept of narrative reading prevailing in literature classes is largely similar (Fialho, Zyngier and Miall 2011, 238).

The problem is that most readers neither fulfil this ideal nor aspire to it. Empirical studies have shown that people are generally bad at noticing obvious errors that are "hidden" in non-emphatic positions in a text, e.g.: "After an air crash, where should the survivors be buried?" or notoriously, "How many animals of each sort did Moses put in the Ark?" (see Emmott, Sanford and Dawydiak 2007 for a review). This is because readers with developed reading skills rarely take in one word at a time the way it has been suggested by Rosenblatt. Rather, their attention for wording and meaning is partly allocated in retrospect, depending on emergent structure. Unless highly unfamiliar or unexpected in themselves, discrete formulations largely become salient in a reader's attention and memory only if they prove significant for the continued narrative (see also Perry 1979). In this regard, the attention economy of silent narrative reading may not be entirely dissimilar from that of verbal auditory perception as explicated by Susan Blackmore, psychologist and philosopher of mind:

In a noisy room full of people talking you may suddenly switch your attention because someone has said 'Guess who I saw with Anya the other day - it was Bernard'. [...] At this point you seem to have been aware of the whole sentence as it was spoken. But were you really? The fact is that you would never have noticed it at all if she had concluded the sentence with a name that meant nothing to you. (Blackmore 2002, 24)

Accordingly, readers' memory for precise wording is known to be generally poor (e.g., Dixon and Bortolussi 2013, 2). There seems to be relatively little innate capacity on the part of the reader to thoroughly register and interpret textual detail. More importantly, there may also be relatively little spontaneous need to do so. For an approximate illustration, read the following narrative passage from Hemingway's A Farewell to Arms. Read as naturally as possible:

There was a battery of naval guns that had gotten on his nerves. I would recognize them because of their flat trajectory. You heard the report and then the shriek commenced almost instantly. They usually fired two guns at once, one right after the other, and the fragments from the burst were enormous. He showed me one, a smoothly jagged piece of metal over a foot long. It looked like babbitting metal.

"I don't suppose they are so effective," Gino said.

"But they scare me. They all sound as though they came directly for you. There is the boom, then instantly the shriek and burst. What's the use of not being wounded if they scare you to death?” (Hemingway 1962 [1929], 182)

Consider now the expression "babbitting metal" as used in this passage. Most readers probably never encountered the expression before, partly because it 
taps into a specialized domain of knowledge (metallurgy), partly because the standard expression for the phenomenon in question (a type of alloy) is now Babbitt, Babbitt metal, or bearing metal - not babbitting metal. Does this mean that most readers halt at the expression to ponder it as they read, or that they put the printed book aside to consult external information sources before they continue reading? ${ }^{6}$ I believe that most readers are not especially bothered by such an isolated instance of meaning opacity, if they notice it in the first place. More often than not Hemingway's use of "babbitting metal” probably has no deeper bearing on further text experience.

Although one's inattention vis-à-vis the precise meaning of the expression would show on an objectively administered comprehension test, it is relatively unlikely to prompt one of those moments when the narrative stops making sense, subjectively speaking. And if an unfamiliar expression such as "babbitting metal" can remain largely inconspicuous, how about all the familiar expressions that form the bulk of a narrative? For instance, does ambiguous anaphoric reference as exemplified by the wealth of pronouns in the opening of the excerpt ("his nerves" vs. "I would recognize" vs. "You heard"; emphasis mine) always cause readers to pause and reflect until they are able to determine who is who? Experimental research (Sanford and Emmott 2013, 72-102) suggests that this is not necessarily the case. Rather, it seems that a more large-scale comprehension failure (e.g., concerning a key event or a decision potentially affecting the main course of events) is typically needed for a reader to realize that she has been inattentive, and to deliberately act on her inattention by making a pause in reading.

\subsection{Second Set of Consequences for Text Experience}

Now that it has been proposed that readers of print narrative are neither very attentive nor bothered by their inattention, what conclusions can we draw from this proposal in relation to audiobook listening, the similarity between the two media, and the possible function of this similarity? The pace of audiobook listening is externally imposed. ${ }^{7}$ In this connection, theorists (e.g., Wittkower 2011) have pointed to the fact that the digital audio players of today do not allow lis-

6 Interruptions for information search are believed by some scholars to be more common in ereading, where search engines are often integrated in the reading device (Wolf and Barzillai 2009).

7 However, some audio software enables the listener to adjust the playback speed, a feature purportedly gaining traction in expository reading (Garber 2015). 
teners to comfortably circle back in a narrative to rehear discrete passages. Navigating back and forth in an audio narrative remains greatly imprecise, which has led to the assumption that it is not done very frequently, as compared to rereading in print. But is it really correct to assume that readers of print narrative frequently circle back to unattended passages - unless their understanding of key events is severely weakened? My above argument suggests that it is not (see also Toolan 2008).

The question arises why readers and listeners, in contrast to the attitudes commended by literary scholars and educators, may worry so little about their grasp of what they read or listen to. A possible explanation is that circling back to unattended passages may be useful for systematic reflection of the scholarly kind, but way too costly in terms of another inherent function of narrative reception: the recipient's sense of mental fluency. It is with the fluency of their experience in mind, I would like to suggest, that recipients prefer trying to catch up with a narrative before taking the radical step of rereading or re-listening. The positive value of experienced fluency has been empirically proven. In a meta-analysis of a large corpus of experimental data obtained with visual and (primitive) verbal stimuli (Reber, Schwarz and Winkielman 2004), processing fluency has been identified as the single most reliable predictor of aesthetic pleasure. Aesthetic pleasure, i.e., the instant joy or sense of beauty triggered by a stimulus without any intermediate reasoning, is in turn a massive factor in leisure reading and listening. As a motivation for the recipient to stick with a narrative in whatever medium, it probably outperforms any need for systematic reflection.

Moreover, an artificially induced sense of fluency has been expressly mentioned as an important benefit of portable audio usage overall. Survey respondents have reported that their hectic daily errands can become significantly more pleasurable with music or narrative playing through a headset, precisely due to the unifying, uninterrupted nature of the auditory stimulus (Bull 2007, 24-49). That this experienced fluency is far from synonymous to the constancy of one's attention vis-à-vis the auditory stimulus is obvious in the case of some such listening situations. To the contrary, audiobook listeners largely and willingly engage in a continuous "drifting in and out of attention" (Wittkower 2011, 222). Thus it seems that periodic inattention can contribute to a listener's experience of fluency instead of disturbing it. If the same applies to print reading, the intuition that audiobooks invite more inattentive processing is true only in part and only in its weaker form. Importantly, it loses much of its original significance as soon as we abandon traditional academic preconceptions concerning the inherent levels and value of focal attention in the reception of narrative. 


\section{Third Similarity: The Occasional Richness of the Recipient's Phenomenal Consciousness}

\subsection{Third Intuition}

The third and final cross-medial similarity to be explored here is the occasional richness of the recipient's phenomenal consciousness. What is phenomenal consciousness? Phenomenal consciousness is closely linked to the previous two aspects of the recipient's experience, i.e., mental imagery and attention. In any given situation, a subject is phenomenally conscious if there is something that gives her the impression of what it is like for her, in terms of her subjective experience of the world around her, to be in that situation. For instance, an audiobook listener is phenomenally conscious of a sensory stimulus from the environment, say the smell of exhaust fumes, if this stimulus somehow informs her experience proper of the listening session.

There is a long-standing philosophical debate concerning the nature of phenomenal consciousness. Some philosophers (Dennett 1991) claim that phenomenal consciousness is inherently thin, i.e., that it can only encompass what is in the focus of one's attention. On such a thin account, an audiobook listener could never become phenomenally conscious of a smell from the environment without having to shift her attention away from the audiobook. On the other side of the spectrum, rich accounts of phenomenal consciousness (Searle 1992) suggest that our consciousness is constantly flooded with non-focal stimuli. On this account, the sheer presence of exhaust fumes in one's environment automatically entails that their smell is consciously experienced. These two radical accounts have partly been reconciled in a complex empirical study (Schwitzgebel 2007). The findings of this study suggest that in naturalistic everyday situations, phenomenal consciousness tends to alternate between a thinner and a richer set. In other words, phenomenal consciousness is only occasionally rich, sometimes encompassing non-focal aspects of a situation (e.g., the smell of exhaust fumes during an urban audio session), sometimes not.

This observation has bearing on the third intuition concerning audiobook listening. The intuition goes roughly as follows: Compared to print reading, audiobook listening is more environmentally situated. Or even more strongly: Unlike print reading, audiobook listening is environmentally situated. The intuition is meant to signify that, because an audiobook listener typically engages in the simultaneous navigation of an environment, her text experience is more contingent on the concurrent environment experience. As a consequence, the overall experience is more arbitrary, subject to external variables. Between two different 
environments, one's listening experience of a given narrative should then vary more strongly than one's reading experience of the same narrative. This is how the intuition has been framed in scholarly writing (Wittkower 2011). Once again, the weaker version of the intuition is probably true to some extent, yet it deserves revision with regard to the nature of print reading.

\subsection{Third Misconception}

Translated into the terms of the phenomenal consciousness debate, audiobook listening is assumed to generally entail richer consciousness relative to print reading. What is more, in narrative scholarship print reading is often assumed to generally entail more or less radically thin phenomenal consciousness. This is the misconception that needs to be dealt with. It is epitomized in one of the basic tenets of the so-called transportation framework, an influential model of narrative reading: Narrative (print) reading transports you away from your physical environment. The transportation framework, first introduced in narrative studies by psychologist Richard Gerrig and further developed especially by Melanie Green and colleagues (e.g., Green and Brock 2000), has significantly contributed to our understanding of narrative reading overall. What should be questioned is the idea that transportation into a narrative experience, defined as "an integrative melding of attention, imagery, and feelings" (Green and Brock 2000, 701), occurs at the cost of one's experience of the physical environment.

In a widely used psychometric instrument, transportation is modelled to decrease to the extent that readers report being conscious of their surroundings. The authors support their model by saying that "a transported reader may not notice others entering the room” (Green and Brock 2000, 702). But unless print reading is for some reason exempt from the general workings of phenomenal consciousness, environment occasionally becomes salient in a reader's experience, too. There is no reason why attention for - and mental imagery prompted by - a printed narrative should foreclose all conscious environment experience and vice versa. Consider for instance the following narrative passage from Hemingway's The Garden of Eden:

The breeze from the sea was blowing through the room and [David] was reading with his shoulders and the small of his back against two pillows and another folded behind his head. He was sleepy after lunch but he felt hollow with waiting for her and he read and waited. (Hemingway 1995 [1986], 45) 
The situation rendered in this passage takes place in a rented vacation room during Catherine and David's honeymoon in the Mediterranean. Apart from David's instantaneous impatience, the overall atmosphere at this stage of the story is rather relaxed and idyllic. Imagine a reader reading the passage in a physical setting, or even overall disposition, overlapping with David's. The narrative is then likely to enhance this reader's phenomenal experience of her own environment, say the pressure of physical pillows behind her back or a breeze that happens to be cooling down her skin on a hot day. The overlap between physical and fictional environment may also prop her enactive mental imagery of the situation rendered in the narrative (Kuzmičová 2016). In such cases of relatively close overlap, the physical environment can thus affect mental imagery in a manner precisely opposite to within-modality interference as mentioned earlier in Section 3.1. Compared to reading the same passage on a crowded bus, where one may deliberately strive for a thinner mode of consciousness in order to screen off tiresome outer stimuli (the smell of exhaust fumes, the roar of the engine, the chatter of fellow passengers), the environment is not experienced as wholly extraneous to the narrative. For a brief instant at least, the reader experiences rich phenomenal consciousness.

\subsection{Third Set of Consequences for Text Experience}

Environmental propping of mental imagery is just one, and possibly relatively sparse, way in which a reader's phenomenal consciousness occasionally becomes rich. Environment experience can also link to text experience on a more general, i.e., more generally aesthetic, level. Let us return to the crowded bus scenario. For most readers a crowded bus represents a less inherently pleasing environment than a coastal vacation dwelling. But its lack of inherent pleasure can vary on a scale. On one end of the scale, an environment can be so unpleasant that one is incapable of reading in it at all. Next on the scale are situations when an environment can only be used for reading provided that the reader succeeds in screening off environmental stimuli altogether, achieving a radically thin mode of phenomenal consciousness.

Next, however, are situations when an environment is experienced as only comparably unpleasant, allowing for a comparably rich mode of phenomenal consciousness during reading. One possible consequence of such situations, then, is a transfer of aesthetic pleasure (or simply aesthetic transfer) between text and environment. This means that the value-positive experience prompted by a narrative per se can make the concurrent environment experience less unpleasant. In highly pleasurable environments, aesthetic transfer may also occur 
in the opposite direction. In other words, even a crowded bus can become a distinctly nice and cosy place to be in with an aesthetically pleasing book, and a relatively distressing book can afford a more fluent and pleasing experience once you get off the bus to read on a romantic park bench (for more on this see Kuzmičová 2016).

Aesthetic transfer, I would like to suggest, is the functional side proper of the recipient's rich phenomenal consciousness. It operates - occasionally - in audiobook listening and print reading alike. A population of portable audio player users expressly reported in a survey (Bull 2007, 38-49) that an audiobook or piece of music played through a headset allows them to literally project aesthetic pleasure onto environments (e.g., crowded urban settings) where none would be found otherwise. Moreover, the aesthetic pleasure taken in a narrative likely affects the way an environment is later remembered, and vice versa. It has been suggested in this context that an audiobook "binds memory in ways very different from written text, due to the simultaneous experience of an arbitrarily related visual field" (Wittkower 2011, 230; emphasis mine). However, there is some evidence that readers, too, vividly recall their changing reading environments in a longer time frame. A research team led by literary scholar Andrew Elfenbein collected an extensive set of reading memories written down between 1777 and 1915. Looking into what aspects of people's reading experiences were typically mentioned upon long-term recall, Elfenbein's analysis (2012) revealed that detailed recollections of reading environment were strongly represented, and consistently correlated with memories of story content. More anecdotally, novelist Marcel Proust went so far as to claim that books read in the more distant past were above all the chronicles of our physical, mundane life and "of the places and days when and where we engaged" (Proust 2011, 18) in reading them. Such accounts of print reading diverge from the intuition that print reading, unlike audiobook listening, is not environmentally situated, or that print narrative transports readers away from their physical environment.

\section{Conclusion}

Comparisons between established and emergent cultural practices usually highlight relative weaknesses in the latter. If audiobooks were meant to replace print or reading entirely, a thorough empirical investigation of such weaknesses would be critical. For the time being, it is probably fair to say that audiobooks cannot compete with print in their affordances for academic reading strategies relying on close attention to verbal artistry and subtle patterns of meaning organization. 
On the other hand, it is also fair to say that academic reading strategies thus defined concern a relatively small readership.

In this chapter I isolated three features of audiobook listening which I unpacked with the help of three intuitions concerning alleged differences visvis print reading: the enactive nature of the recipient's mental imagery, the relative poverty of the recipient's attention, and the occasional richness of the recipient's phenomenal consciousness. Rather than presenting them as distinctive of the audiobook, I chose to point at their ubiquity in narrative text reception more generally. It is a virtue rather than a weakness of the audiobook medium that it makes these features emerge in the centre of theoretical attention, disproving common misconceptions concerning print reading. These misconceptions in turn are largely caused by the traditional lack of interest, amongst reader response theorists, in non-academic reading strategies (for a classical example, see Culler 1980).

The three cross-medial similarities may indeed be inversely related to continuous in-depth reflection. Enactive mental imagery (first similarity), compared to a notion of picturesque imaging (first misconception), erases the mental distance required for reflection, and there is nothing overtly systematic or analytical about the non-self-centred daydreaming it enables (first set of consequences). Relatively poor attention (second similarity), unlike its opposite (second misconception), clearly disagrees with academic strategies of reading. In these strategies, any subjective sense of fluency (second set of consequences) becomes necessarily disrupted. Finally, an acknowledgement of rich phenomenal consciousness (third similarity) poses a problem to a view of reading freed from the contingencies of a particular environment (third misconception). It makes a narrative text an even less stable, i.e., analysable, object than traditionally assumed. In fact, the idea of aesthetic transfer from text to environment (third set of consequences) presupposes a shift in the primary role of narrative - from an object of reflection to a means of achieving hedonistic states of mind. It must be noted that the long-term cognitive benefits of in-depth reflection remain indisputable (Wolf and Barzillai 2009). Yet audiobooks are often played in situations precluding such reflection anyhow, and should therefore be valued for what they do facilitate: the recipient's wellbeing through daydreaming, fluency, and overall aesthetic pleasure, as also facilitated by non-academic ways of print reading. 


\section{Works Cited}

Birkerts, Sven. 1994. The Gutenberg Elegies: The Fate of Reading in an Electronic Age. New York: Fawcett Columbine.

Blackmore, Susan. 2002. "There Is No Stream of Consciousness." Journal of Consciousness Studies 9.5-6: 17-28.

Bolter, Jay D., and Richard Grusin. 2000. Remediation: Understanding New Media. Cambridge: MIT Press.

Bull, Michael. 2007. Sound Moves: iPod Culture and Urban Experience. London: Routledge.

Chapelle Wojciehowski, Hannah, and Vittorio Gallese. 2011. "How Stories Make Us Feel: Toward an Embodied Narratology." California Italian Studies 2.1. ismrg_cisj_8974. https://escholarship.org/uc/item/3jg726c2 (18 November 2014).

Connell, Louise, and Dermot Lynott. 2012. "Strength of Perceptual Experience Predicts Word Processing Performance Better than Concreteness or Imageability.” Cognition 125.3: $452-465$.

Culler, Jonathan. 1980. "Prolegomena to a Theory of Reading." In: The Reader in the Text: Essays on Audience and Interpretation. Eds. Susan Suleiman and Inge Crosman. Princeton: Princeton University Press. 46-66.

De Beni, Rossana, and Angelica Moè. 2003. "Presentation Modality Effects in Studying Passages. Are Mental Images Always Effective?” Applied Cognitive Psychology 17.3: 309-324.

Dennett, Daniel C. 1991. Consciousness Explained. Boston: Little, Brown and Co.

Dixon, Peter, and Marisa Bortolussi. 2013. "Construction, Integration, and Mind Wandering in Reading." Canadian Journal of Experimental Psychology/Revue canadienne de psychologie expérimentale 67.1: 1-10.

Dowrick, Christopher et al. 2012. "Get into Reading as an Intervention for Common Mental Health Problems: Exploring Catalysts for Change.” Medical Humanities 38.1: 15-20.

Eardley, Alison F., and Linda Pring. 2011. "Exploring the Impact of Sucking Sweets on Flavour Imagery." Journal of Cognitive Psychology 23.7: 811-817.

Elfenbein, Andrew. 2012. "Long-Term Memory for Narrative Fiction: Evidence from the Archives." Thirteenth Biennial Meeting of the International Society for the Empirical Study of Literature and Media. Montreal.

Emmott, Catherine, Anthony J. Sanford, and Eugene J. Dawydiak. 2007. "Stylistics Meets Cognitive Science: Studying Style in Fiction and Readers' Attention from an Inter-Disciplinary Perspective." Style 41.2: 204-226.

Fialho, Olivia, Sonia Zyngier, and David Miall. 2011. "Interpretation and Experience: Two Pedagogical Interventions Observed." English in Education 45.3: 236-253.

Fischer, Martin H., and Rolf A. Zwaan. 2008. "Embodied Language: A Review of the Role of the Motor System in Language Comprehension." The Quarterly Journal of Experimental Psychology 61.6: 825-850.

Garber, Megan. 2015. “The Rise of Speed-Listening.” The Atlantic (24 June). http://www.theatlantic.com/technology/archive/2015/06/the-rise-of-speed-listening/396740/ (29 June 2015).

Green, Melanie C., and Timothy C. Brock. 2000. "The Role of Transportation in the Persuasiveness of Public Narratives." Journal of Personality and Social Psychology 79.5: 701-721. 
Hancher, Michael. 2011. "Learning from LibriVox." In: Audiobooks, Literature, and Sound Studies. Ed. Matthew Rubery. New York: Routledge. 199-215.

Hemingway, Ernest. 1962 [1929]. "A Farewell to Arms.” Three Novels. New York:

Scribner. 1-332.

Hemingway, Ernest. 1995 [1986]. The Garden of Eden. New York: Scribner.

Jaffe, Eric. 2014. "Your Brain On Audio Books: Distracted, Forgetful, And Bored." Co.Design

(12 February). http://www.fastcodesign.com/3026224/evidence/

your-brain-on-audio-books-distracted-forgetful-and-bored (18 November 2014).

Jajdelska, Elspeth et al. 2010. "Crying, Moving, and Keeping It Whole: What Makes Literary Description Vivid?” Poetics Today 31.3: 433-463.

Kuzmičová, Anežka. 2016. "Does It Matter Where You Read? Situating Narrative in Physical Environment." Communication Theory 26.2.

Kuzmičová, Anežka. 2014. "Literary Narrative and Mental Imagery: A View from Embodied Cognition.” Style 48.3: 275-293.

Kuzmičová, Anežka. 2012. "Presence in the Reading of Literary Narrative: A Case for Motor Enactment." Semiotica 189.1/4: 23-48.

Laidman, Jenni. 2012. “Audiobooks: Are They Really the Same as Reading?" Chicago Tribune (6 April).

http://articles.chicagotribune.com/2012-04-06/entertainment/ct-prj-0408-audiobookoks-20120406_1_audiobooks-first-book-audible-com (18 November 2014).

Mangen, Anne, and Don Kuiken. 2014. "Lost in an iPad: Narrative Engagement on Paper and Tablet." Scientific Study of Literature 4.2: 150-177.

Miall, David S. 2006. Literary Reading: Empirical \& Theoretical Studies. New York: Peter Lang. Murphy Paul, Annie. 2013. "The New Marshmallow Test: Resisting the Temptations of the Web." The Hechinger Report (3 May).

http://hechingerreport.org/content/the-new-marshmallow-test-resisting-the-temptations-of-the-web_11941 (18 November 2014).

Oatley, Keith. 2011. Such Stuff as Dreams: The Psychology of Fiction. Chichester: Wiley-Blackwell.

Perry, Menakhem. 1979. "Literary Dynamics: How the Order of a Text Creates Its Meanings [With an Analysis of Faulkner's "Rose for Emily"]." Poetics Today 1.1-2: 35-64.

Proust, Marcel. 2011. On Reading. Trans. Damion Searls. London: Hesperus Press.

Reber, Rolf, Norbert Schwarz, and Piotr Winkielman. 2004. "Processing Fluency and Aesthetic Pleasure: Is Beauty in the Perceiver's Processing Experience?” Personality and Social Psychology Review 8.4: $364-382$.

Rosenblatt, Louise M. 1994 [1978]. The Reader, the Text, the Poem: The Transactional Theory of the Literary Work. Carbondale: Southern Illinois University Press.

Rubery, Matthew, ed. 2011a. Audiobooks, Literature, and Sound Studies. New York: Routledge.

Rubery, Matthew. 2011b. "Introduction: Talking Books.” In: Audiobooks, Literature, and Sound Studies. Ed. Matthew Rubery. New York: Routledge. 1-21.

Sanford, Anthony J., and Catherine Emmott. 2013. Mind, Brain and Narrative. Cambridge: Cambridge University Press.

Schumacher, Eric H. et al. 2001. "Virtually Perfect Time Sharing in Dual-Task Performance: Uncorking the Central Cognitive Bottleneck.” Psychological Science 12.2: 101-108. 
Schwitzgebel, Eric. 2007. "Do You Have Constant Tactile Experience of Your Feet in Your Shoes? Or Is Experience Limited to What's in Attention?" Journal of Consciousness Studies 14.3: 5-35.

Searle, John R. 1992. The Rediscovery of the Mind. Cambridge: MIT Press.

Smallwood, Jonathan et al. 2013. "Escaping the Here and Now: Evidence for a Role of the Default Mode Network in Perceptually Decoupled Thought." Neurolmage 69: 120-125.

Spence, Charles, and Ophelia Deroy. 2013. "Crossmodal Mental Imagery.” In: Multisensory Imagery. Eds. Simon Lacey and Rebecca Lawson. New York: Springer. 157-183.

Thompson, Evan. 2007. “Look Again: Phenomenology and Mental Imagery.” Phenomenology and the Cognitive Sciences 6: 137-170.

Toolan, Michael. 2008. “Audiofiction: No Time for Deep Thoughts and Feelings?" On-line Proceedings of the 25th Annual Conference of the International Poetics and Linguistics Association. http://www.pala.ac.uk/uploads/2/5/1/0/25105678/toolan2008. pdf (18 November 2014).

Troscianko, Emily T. 2013. "Reading Imaginatively: The Imagination in Cognitive Science and Cognitive Literary Studies.” Journal of Literary Semantics 42.2: 181-198.

Varao Sousa, Trish L., Jonathan S. A. Carriere, and Daniel Smilek. 2013. "The Way We Encounter Reading Material Influences How Frequently We Mind Wander." Frontiers in Psychology 4.892: 1-8.

Wittkower, D. E. 2011. "A Preliminary Phenomenology of the Audiobook.” In: Audiobooks, Literature, and Sound Studies. Ed. Matthew Rubery. New York: Routledge. 216-231.

Wolf, Maryanne, and Mirit Barzillai. 2009. "The Importance of Deep Reading." Educational Leadership 66.6: 32-37. 